\title{
Hydroxyapatite/collagen composite graft for posterior lumbar interbody fusion: a comparison with local bone graft
}

\author{
Toshitaka Yoshii ${ }^{*}$, Motonori Hashimoto, Satoru Egawa, Takashi Hirai, Hiroyuki Inose and Atsushi Okawa
}

\begin{abstract}
Background: Autologous bone has been used for posterior lumbar intervertebral fusion (PLIF). However, harvesting autologous bone graft is associated with donor site complications. We previously developed a hydroxyapatite/collagen ( $\mathrm{HAp} / \mathrm{Col}$ ) composite as an osteoconductive artificial bone, characterized by having a highly porous structure with sponge-like elasticity. This study aims to investigate the effectiveness of HAp/Col composite with bone marrow aspirate (BMA) as a graft substitute in PLIF for the treatment of lumbar spinal diseases.

Methods: This study prospectively investigated patients who received one-level PLIF. For the interbody fusion, two titanium cages were inserted. On the one side of interbody space, HAp/Col composite incorporated with BMA filling the titanium cage was grafted. On the other side, local bone graft (LBG) harvested during decompressive laminotomy was grafted and then one-level instrumentation using pedicle screws was performed. The target levels were at $L 2 / 3$ in 2 cases, L3/4 in 3 cases, L4/5 in 36 cases, and L5/S in 5 cases. We evaluated clinical symptoms and radiological outcomes of 46 patients and compared the fusion status of HAp/Col composite with that of LBG.
\end{abstract}

Results: The 1-year postoperative CT evaluation demonstrated that, in the HAp/Col, a complete fusion was observed in 38 patients (82.6\%), whereas in the LBG, a complete fusion was observed in 35 patients (76.1\%). There were no statistical differences between the HAp/Col and LBG. In the HAp/Col, incomplete fusion was observed in five patients (10.9\%) and non-fusion in two patients (4.3\%), and in the LBG, incomplete fusion was observed in nine patients (19.6\%) and non-fusion in two patients (4.3\%). At 2 years after the surgery, complete fusion increased to 44 patients (95.7\%) in the HAp/Col and 41 patients (89.1\%) in the LBG. There were no significant differences in the clinical scores for lumbar spine between patients with fusion and non-fusion.

Conclusions: The HAp/Col composite with BMA in the titanium cage can be effectively used as an alternative to conventional autologous LBG for intervertebral spinal fusion.

Trial registration University hospital Medical Information Network, UMIN000045010, July 30th, 2021, Retrospectively registered, https://www.umin.ac.jp/english/.

Keywords: Graft substitute, Hydroxyapatite with collagen, Local bone graft, Posterior lumbar interbody fusion, Fusion rate

*Correspondence: yoshii.orth@tmd.ac.jp

Department of Orthopedic Surgery, Tokyo Medical and Dental University,

1 Chome-5-45 Yushima, Bunkyo City, Tokyo 113-8510, Japan

\section{Introduction}

The autologous bone graft has been the gold standard for lumbar spinal fusion. Furthermore, the autologous bone harvested from the iliac crest or local bone from the spinous process and laminae has been used with cages to original author(s) and the source, provide a link to the Creative Commons licence, and indicate if changes were made. The images or other third party material in this article are included in the article's Creative Commons licence, unless indicated otherwise in a credit line to the material. If material is not included in the article's Creative Commons licence and your intended use is not permitted by statutory regulation or exceeds the permitted use, you will need to obtain permission directly from the copyright holder. To view a copy of this licence, visit http://creativecommons.org/licenses/by/4.0/. The Creative Commons Public Domain Dedication waiver (http://creativecommons.org/publicdomain/zero/1.0/) applies to the data made available in this article, unless otherwise stated in a credit line to the data. 
the intervertebral space for posterior lumbar intervertebral fusion (PLIF) [1, 2]. However, significant incidences of complications at the donor site associated with harvesting bone from the iliac crest, including donor site pain, hematoma, infections, fracture of the ilium, sensory disturbance, and cosmetic disability, were reported [3]. Moreover, local bone harvested from the spinous process and laminae is limited in amount, especially in revision surgery.

The hydroxyapatite/collagen ( $\mathrm{HAp} / \mathrm{Col}$ ) composite was previously developed as an artificial bone substitute with distinctive characteristics [4-8]. HAp/Col composite is characterized by having a highly porous structure composed of collagen fibers with HAp nanocrystal deposits. HAp/Col composite has a sponge-like elasticity and biocompatibility. A variety of graft substitutes have been increasingly studied for spinal fusion [9-11]. Most graft materials, including $\mathrm{HAp} / \mathrm{Col}$ composite, have been proven both biocompatible and osteoconductive; however, few osteoinductive properties were observed in the materials themselves $[12,13]$. Therefore, it is preferable to use biologically active tissue-inducing substances or cells with the ceramics.

Animal studies have proved that, due to the presence of osteoprogenitor cells and osteoinductive growth factors, bone marrow aspirate (BMA) exhibits osteopromotive properties when combined with porous ceramics [14, 15]. Besides, its osteogenic potential has also been shown in spinal fusion in both animal models and humans [14-18]. BMA has the clinical merits of being autologous and intraoperatively available, with harvesting possible through a simple and safe aspiration [15]. HAp/Col composite has a large surface area, and the nanoscale HA crystals enable it to absorb a large quantity of proteins and other molecules, such as drugs and ions [4]. Therefore, BMA integrated into the $\mathrm{HAp} / \mathrm{Col}$ composite was used, and the graft in a titanium cage was implanted for the intervertebral spinal fusion.

In this study, we investigated the effectiveness of HAp/ Col composite for spinal fusion using a "side-by-side" comparison model. The new HAp/Col composite incorporated with BMA filling the titanium cage was grafted on one side of the interbody space. On the other side, autologous local bone graft (LBG) harvested during decompressive laminotomy was grafted, and then, onelevel instrumentation using pedicle screws was performed. We evaluated and compared the fusion status of both HAp/Col composite and LBG.

\section{Methods}

This study was approved by the institutional review board. This study prospectively investigated 50 consecutive patients who underwent a 1-level PLIF from March
2014 to August 2016. Lumbar spinal canal stenosis with single-level segmental instability was diagnosed in 20 patients, 29 presented with degenerative spondylolisthesis, and 1 had isthmic spondylolisthesis. The patients underwent decompression laminotomy and pedicle screw instrumented PLIF. The patients who had a history of previous lumbar spine surgery, spinal infection, trauma, and multilevel spinal fusion were excluded from the study.

\section{Surgical techniques and preparation of the implants}

The patients were placed in a prone position, and decompressive laminotomy was performed to remove the spinous process and lamina in the region of spinal canal stenosis under general anesthesia. To access the intervertebral disc, the facet joints were removed. The local bone chips extracted during laminotomy were morselized and collected by meticulously removing the covering soft tissues; these morselized bone chips were used as a graft on the control side. Then, the intervertebral disc was removed and the endplate was curetted. After the adequate size of cage was determined using a trial cage, one cage was filled with HAp/Col composite. Another cage was filled with LBG. We used the same-sized two titanium cages for the intervertebral space, with $\mathrm{HAp} / \mathrm{Col}$ composite grafted on the one side and LBG grafted on the other side.

We used scanning electron microscopy (SEM) to demonstrate the morphology of the composite HA. Also, a Hitachi S-24300 scanning electron microscope was used to acquire images (Fig. 1). The pore size and porosity of the porous $\mathrm{HAp} / \mathrm{Col}$ composite were $100-500 \mu \mathrm{m}$ and $95 \%$, respectively.

Approximately, $3 \mathrm{~mL}$ of BMA was aspirated from the posterior iliac crest with 11-gauge Jamshidi bone marrow biopsy/aspiration needle. The harvested BMA was immediately integrated into the $\mathrm{HAp} / \mathrm{Col}$ composite. Then, we inserted HAp/Col composite and LBG with titanium cage (Telamon ${ }^{\circledR}$, Medtronic; O.I.C. Titanium ${ }^{\circledR}$, Stryker) into the intervertebral space. After the insertion of the cages, we used the transpedicular screw/rod instrumentation to perform posterior fixation. On postoperative day 2, all patients were encouraged to begin walking. Furthermore, a soft brace was prescribed for 3 months postoperatively.

\section{Outcomes}

The clinical outcomes were assessed using the scoring system proposed by the Japanese Orthopedic Association (JOA) score [19]. We calculated the recovery rate of JOA score according to the following formula: the recovery rate $(\%)=[($ postoperative score - preoperative score $) /$ $(29-$ preoperative score $)] \times 100$. 

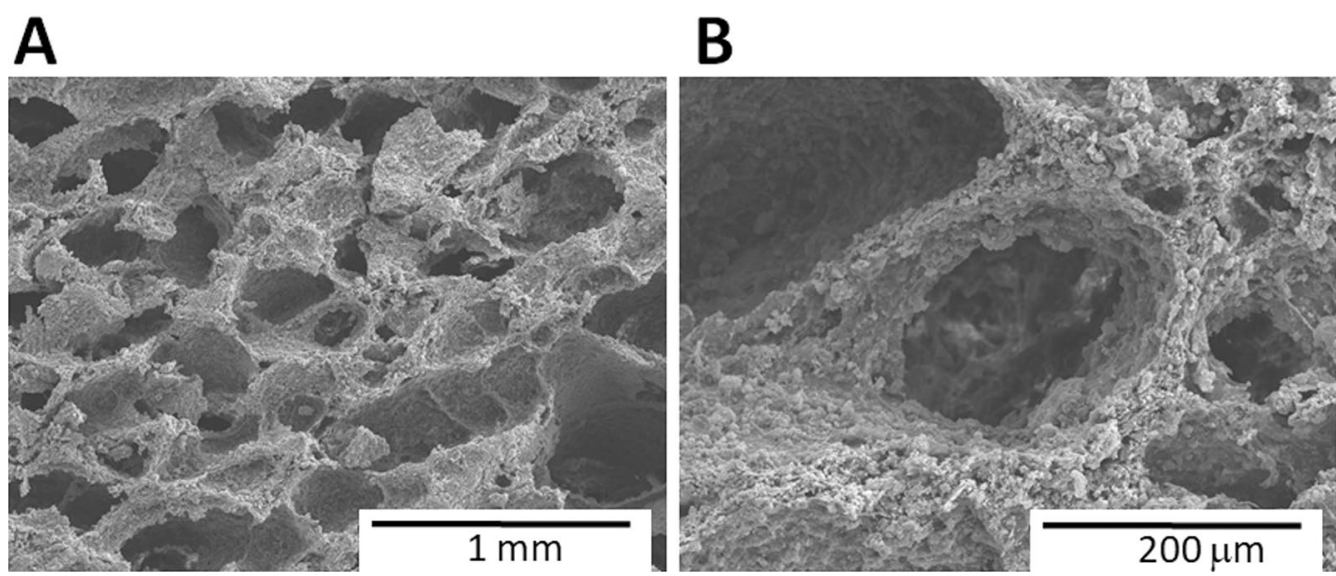

Fig. 1 Scanning electron microscopy (SEM) demonstrates a highly porous structure of the hydroxyapatite/collagen composite (pore size: 100-500 $\mu \mathrm{m}$, porosity: 95\%) (A). High magnification demonstrates macropores and micropores (B)

We evaluated and recorded the fusion status in this study and performed radiographic examinations including pre- and postoperative plain and functional X-rays. We also measured the segmental angles of the operated vertebral levels in a neutral position, as well as in extension and flexion.

The postoperative flexion/extension X-ray shows that angular motion $\geq 3^{\circ}$ was recorded as segmental instability. Cage subsidence was defined as a vertical migration of the cage into the vertebral body by $\geq 2 \mathrm{~mm}$. Screw loosening was defined by a radiolucent zone surrounding the screw thicker than $1 \mathrm{~mm}$. We performed CT evaluation with coronal/sagittal reconstruction before surgery and after surgery at 1 year.

The assessment of the fusion status was performed by two independent spine surgeons in a blinded manner. Based on the reconstructed CT pictures, we simply defined the fusion status as follows: (1) Non-fusion: no bony bridging was observed (Fig. 2A). (2) Incomplete fusion: bony bridging was partly observed, but not completed (Fig. 2B). (3) Complete fusion: a continuous bony bridging was obviously observed (Fig. 2C). We performed CT evaluation for the patients who did not show complete fusion at 2 years after the surgery.

The statistical analysis was carried out using the paired $t$-test and Chi-square test. The confidence interval was set at $95 \%$ and the significance level at $p<0.05$. The $\mathrm{K}$ coefficient (Cohen) was used to evaluate the interobserver agreement in the fusion status scoring. Of the 50 patients included, four patients were excluded (3 with degenerative spondylolisthesis, and 1 suffering from lumbar spinal canal stenosis) because of the absence of CT evaluation ( 2 patients) and because of other diseases ( 2 patients).

\section{Results}

In this study, all the patients tolerated the surgical procedure well. Forty-six patients (92.0\%) [13 males and 33 females, with an average age of 71.3 years (range 51-83)] completed a 1-year follow-up evaluation (Table 1). The target levels were at L2/3 in 2 cases, L3/4 in 3 cases, L4/5 in 36 cases, and L5/S in five cases.

After the surgery, the neurological symptoms improved. The preoperative average JOA score was $15.8 \pm 3.0$ (range 9-23) points, and the postoperative JOA score improved to $25.3 \pm 2.7$ (range 21-29). The average recovery rate was $71.1 \%$ (Fig. 3 ). Of the 50 cases initially included in this study, incidental dural tear occurred in 1 case, which was repaired intraoperatively. A femoral neck fracture occurred in 1 case during the follow-up, and a hip surgery was performed on the patient.

In the fusion status evaluation using a reconstruction CT scan, the interobserver reliability revealed a good agreement (Cohen's Kappa score: 0.75$)$. CT evaluation

(See figure on next page.)

Fig. 2 Fusion status evaluated by computed tomography $(C T)$ at 1 year postoperatively. Left lane: HAP/Col graft, Right lane: Local bone graft. A Non-fusion: no obvious bony bridging was observed. Clear radiolucent line between the graft and endplate or cyst formation was observed. B Incomplete fusion: bony bridging was partly observed, but not completed. The endplates were still visible. C Complete fusion: a continuous bony bridging was obviously observed 

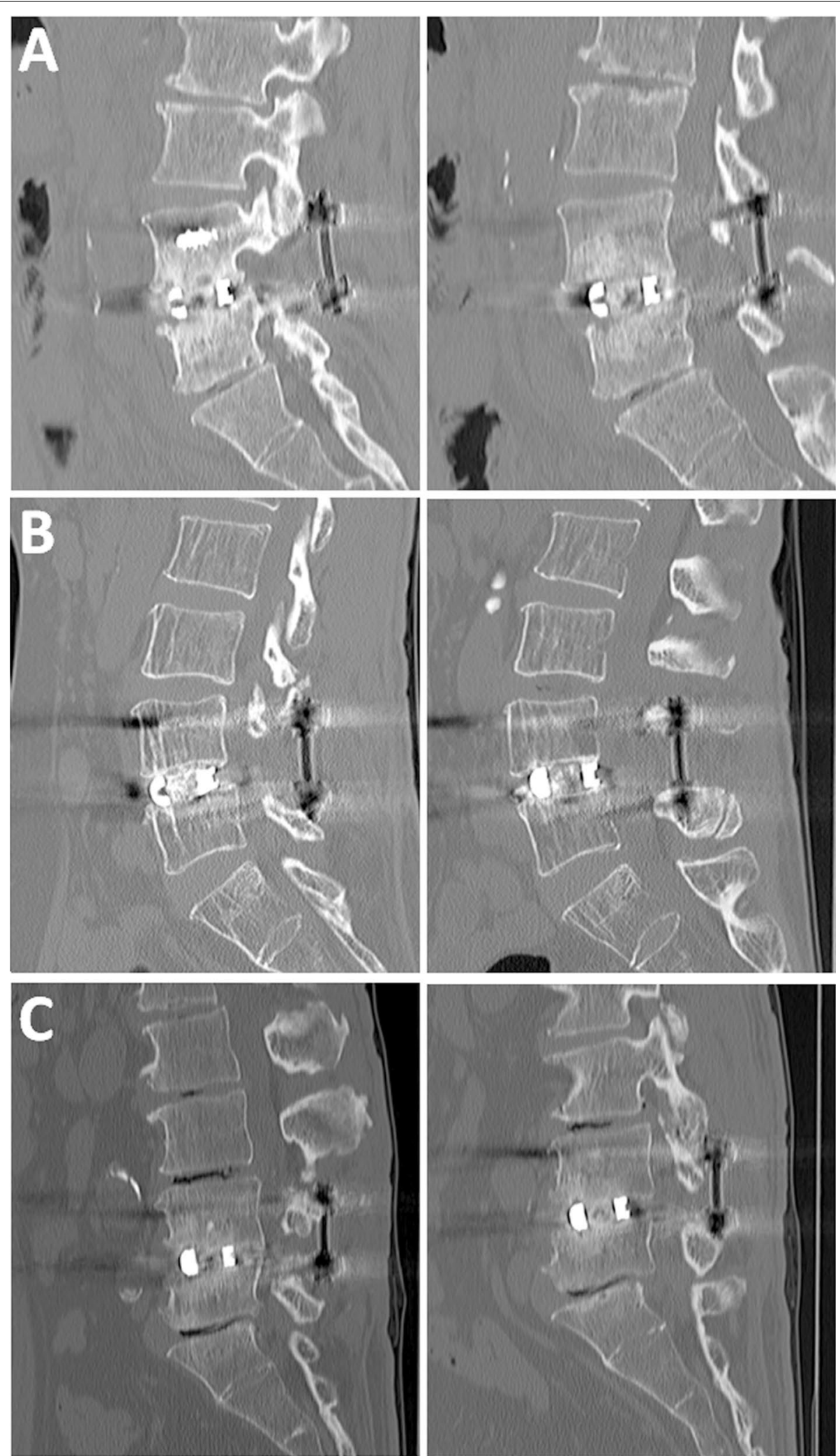

Fig. 2 (See legend on previous page.) 
Table 1 Demographics

\begin{tabular}{ll}
\hline 1-level PLIF case, No & $\mathbf{4 6}$ \\
\hline Male/female & $13 / 33$ \\
Age & $71.3(51-83)$ \\
Diseases & $21(3.7 \%)$ \\
degenerative spondylolisthesis & 26 \\
Lumbar spinal canal stenosis & 19 \\
isthmic spondylolisthesis & 1 \\
Level & \\
L2/3 & 2 \\
L3/4 & 3 \\
L4/5 & 36 \\
L5/S & 5 \\
Pre JOA score (points) & $15.8 \pm 3.0$ \\
Post JOA score (1 year) & $25.3 \pm 2.7$ \\
Recovery rate (\%) & $71.1 \pm 21.5$ \\
Pre-local lordosis (degrees) & $12.0 \pm 7.7$ \\
Post-local lordosis (1 year) & $12.9 \pm 7.0$ \\
\hline
\end{tabular}

at 1 year postoperatively demonstrated that, in the HAp/ Col, a complete fusion was observed in 38 patients (82.6\%), whereas in the LBG, it was observed in 35 patients $(76.1 \%)$. There were no statistical differences between the HAp/Col and LBG (Table 2). On the other hand, in patients who did not show complete fusion at 1 year, in the $\mathrm{HAp} / \mathrm{Col}$, incomplete fusion was observed in five patients $(10.9 \%)$ and non-fusion in two patients (4.3\%), and in the LBG, incomplete fusion was observed in nine patients (19.6\%) and non-fusion in two patients (4.3\%). A complete fusion in the HAp/Col increased to 44 patients $(95.7 \%)$ and 41 patients $(89.1 \%)$ in the LBG at 2 years after the surgery.

In the dynamic X-rays, we observed that only 1 case (2.2\%) exhibited obvious segmental instability $\left(>3^{\circ}\right.$ of angular motion) at 1 year after surgery. The subsidence of the cage was found in 12 patients (26.1\%), whereas no
Table 2 Fusion status by CT evaluation

\begin{tabular}{lccc}
\hline Fusion status & HAp/Col $(\boldsymbol{n}=\mathbf{4 6})$ & LBG $(\boldsymbol{n}=\mathbf{4 6 )}$ & $\boldsymbol{P}$ value \\
\hline 1 year & & & \\
Non-fusion & $2(4.3 \%)$ & $2(4.3 \%)$ & 0.32 \\
Incomplete & $5(10.9 \%)$ & $9(19.6 \%)$ & \\
$\quad$ Complete & $38(82.6 \%)$ & $35(76.1 \%)$ & \\
2 years & & & \\
$\quad$ Non-fusion & $0(0 \%)$ & $0(0 \%)$ & 0.24 \\
Incomplete & $2(10.9 \%)$ & $5(19.6 \%)$ & \\
Complete & $44(95.7 \%)$ & $41(89.1 \%)$ & \\
\hline
\end{tabular}

patients showed cage dislodgement. There was apparent screw loosening in 3 cases (6.5\%). The local alignment (Cobb angle) was enhanced after surgery, but reduced to the preoperative level at 1 year (Fig. 3).

We further compared the group with complete fusion at both cages and the group with incomplete/non-fusion at either of the cages. There were no significant differences in baseline demographics and surgical outcomes between the two groups, but the age of patients in the group with incomplete/non-fusion tended to be higher $(p=0.08)$ (Table 3).

\section{Discussion}

Lumbar spine fusion has been a common practice for treating degenerative spinal diseases. The ideal bone graft materials for spinal fusion require osteoinductivity, osteoconductivity, and excellent mechanical properties. Iliac crest bone graft (ICBG) has been traditionally used because it possesses all the characteristics required for an ideal bone graft, which include trabecular structure as an osteoconductive scaffold, osteoinductive bone morphogenetic proteins, and osteogenic cells. However, the significant complications associated with harvesting ICBG

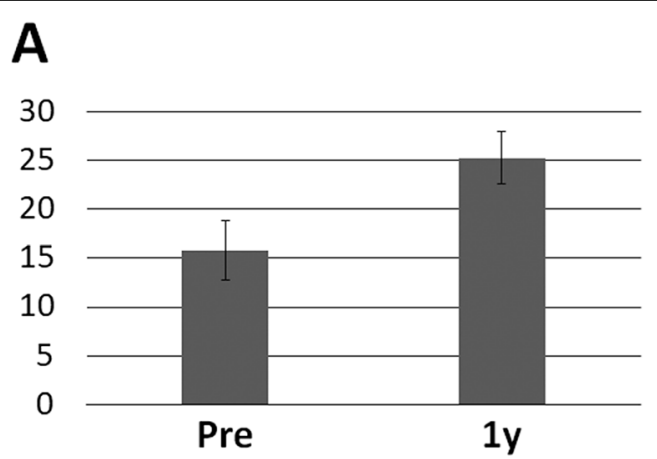

B

(Deg.)

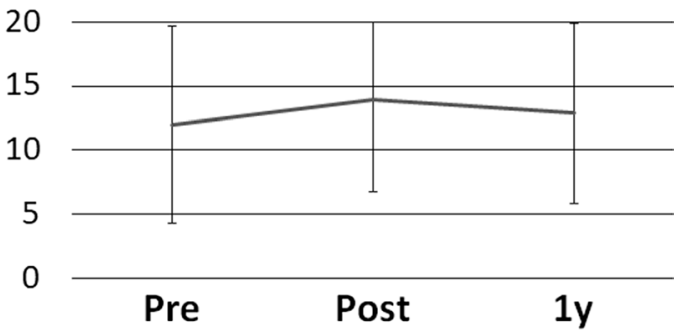

Fig. 3 A Preoperative and postoperative (1 year) neurological scores (JOA score). B Change of local lordosis of the fused segment before and after surgery and at 1 year postoperatively 
Table 3 Cases with complete fusion vs incomplete/non-fusion

\begin{tabular}{llll}
\hline & $\begin{array}{l}\text { Complete } \\
\text { fusion } \\
(\boldsymbol{n}=\mathbf{3 2})\end{array}$ & $\begin{array}{l}\text { Incomplete/ } \\
\text { non-( }=\mathbf{1 4})\end{array}$ & P value \\
\hline Male/female & $8 / 24$ & $4 / 10$ & 0.80 \\
Age & $70.2 \pm 8.3$ & $73.8 \pm 5.2$ & 0.08 \\
Diseases & & & 0.36 \\
Degenerative spondylolisthesis & 16 & 10 & \\
Lumbar spinal canal stenosis & 15 & 4 & \\
Isthmic spondylolisthesis & 1 & 0 & \\
Levels & & & \\
L2/3 & 1 & 1 & 0.89 \\
L3/4 & 2 & 1 & \\
L4/5 & 25 & 11 & \\
L5/S & 4 & 1 & 0.36 \\
Pre-JOA score & $16.0 \pm 3.0$ & $15.1 \pm 3.1$ & \\
Post-JOA score (1 year) & $25.2 \pm 2.9$ & $25.4 \pm 2.4$ & 0.79 \\
Recovery rate (\%) & $70.5 \pm 22.3$ & $72.5 \pm 20.3$ & 0.78 \\
Pre-local lordosis & $12.1 \pm 8.2$ & $11.7 \pm 6.7$ & 0.88 \\
Post-local lordosis (1 year) & $13.4 \pm 11.8$ & $11.8 \pm 5.6$ & 0.49 \\
Subsidence (+) & $9(28.1 \%)$ & $4(28.6 \%)$ & 0.98 \\
\hline
\end{tabular}

have encouraged an ongoing interest in finding alternative graft materials [3].

Calcium-based synthetic materials have been developed as bone graft extenders and/or substitutes. The HAp/Col composite consists of nanoscale hydroxyapatite $(80 \mathrm{w} / \mathrm{w} \%)$ and porcine skin-derived atelocollagen $(20 \mathrm{w} / \mathrm{w} \%)$, and its nanostructure is similar to that of natural bone $[4,6]$. The highly porous structure of HAp/ Col composite can achieve excellent osteoconductivity. In previous studies using various animal models, high osteoconductivity and bioabsorbability of $\mathrm{HAp} / \mathrm{Col}$ composite were demonstrated $[4,6,8]$. Furthermore, once the porous body of $\mathrm{HAp} / \mathrm{Col}$ composite is wetted, it becomes elastic like a sponge and is thus easy to implant into bone defects of various shapes and also be inserted in the PLIF cage.

In the present study, we examined the $\mathrm{HAp} / \mathrm{Col}$ composite integrated with BMA as a graft material implanted in the intervertebral space with the PLIF cage. It is known that the BMA possesses osteogenic potential because it contains both osteoprogenitor cells and bone morphogenetic growth factors $[20,21]$. Connolly et al. reported the osteopromotive property of BMA when injecting autologous marrow into tibial nonunions [22]. Moreover, the use of BMA and osteoconductive scaffolds in posterolateral lumbar fusion was reported in several clinical studies. Epstein et al. reported the efficacy of BMA with TCP/ type I collagen synthetic composite and local autograft as a bone expander in posterolateral spinal fusion [18].
Neen et al. in their prospective study used BMA with hydroxyapatite/type I collagen synthetic matrix in posterolateral lumbar fusion and showed equivalent outcomes when compared with autologous ICBG [23].

In this study, we investigated the efficacy of the HAp/ Col composite with BMA filled in a titanium cage in the posterior approached interbody fusion surgery. There are two major types of cages that are currently used in PLIF: titanium and polyetheretherketone (PEEK) cage. We used titanium cages in this study, because the fusion rate of metal cages is reported to be superior to that of PEEK cages in PLIF [24]. As described previously, $\mathrm{HAp} / \mathrm{Col}$ composite has a sponge-like mechanical property; thus, it is very easily integrated with BMA and packed inside the titanium cage. A previous study also examined this material in the lumbar lateral interbody fusion cage and proved the clinical usefulness of the HAp/Col composite [25]. In this study, we applied the HAp/Col composite in 50 patients and it showed excellent bioavailability; no significant adverse events regarding the $\mathrm{HAp} / \mathrm{Col}$ composite were observed.

We evaluated the intervertebral spinal fusion with $\mathrm{Hap} / \mathrm{Col}$ in a titanium cage by using reconstruction CT, which showed a good interobserver reliability (Kappa score: 0.75). Evaluation based on bony continuity on reconstructed CT is considered as the "golden standard" to monitor the progression of an interbody fusion [26]. Although dynamic lateral flexion and extension radiographs have been used, calculating subtle degrees of motion on flexion/extension films is irreproducible. In a study using sheep, Sandhu et al. showed that only 33\% were judged fused on histological pictures in cases that were judged as radiographic fusion by dynamic X-rays [27]. On the other hand, Cunningham et al. [28], in their study using cages in sheep spine, showed a $100 \%$ correlation between $\mathrm{CT}$ and histological images. Thus, in this study, we used simple fusion criteria based on bony bridging on the reconstructed CT images, which is considered to have substantial accuracy for assessing the interbody fusion.

We compared the HAp/Col composite with BMA with the autologous local bone graft (LBG), which is commonly used for lumbar interbody fusion. The HAp/ Col composite showed a tendency to higher complete fusion rate $(82.6 \%$ and $95.7 \%$, at 1 year and 2 years, respectively), compared with the rate of LBG (76.1\% and $89.1 \%$, at 1 year and 2 years, respectively). A previous systematic review has reported that the fusion rate of single-level PLIF using ICBG or LBG averaged $89.5 \%$ at 2 years postoperatively [29]. The $\mathrm{HAp} / \mathrm{Col}$ composite with BMA in a titanium cage demonstrated a comparable fusion rate to those previously reported using an autologous bone graft. A previous study has 
reported that PLIF using another clinically available calcium phosphate, $\beta$-TCP with BMA, showed a nonfusion rate of $38.6 \%$ at 1 year [30]. The reason for this high non-fusion rate may be explained by the material adaptability to the vertebral endplates above and below the interbody space. Because the $\beta$-TCP has no elastic property, the fitting of the material to the vertebral endplates is not good enough, which results in a lower interface area between the bone and material. On the other hand, the merit of using HAp/Col composite is its excellent capability of fitting to the endplate, which enhances the interface activity and bone formation in the material. Thus, HAp/Col composite would be a more suitable filling material in cages for PLIF. In addition, because the stiff mechanical property of titanium cages can cause shaving to the endplate, which may cause a high rate of subsidence, this may also enhance recruitment of the progenitor cells to the material.

There are some limitations in our study. (1) We used a "side-by-side" comparison model to compare the HAp/ Col composite and LBG as a filling material in cages for PLIF. In this model, the fusion or lack of fusion on the one side may influence the progress of fusion on the opposite side. (2) We used local laminectomy bone as a control instead of using ICBG. However, the LBG has recently been shown to achieve an equivalent fusion rate in one-level fusion. (3) Radiological changes at the adjacent levels were not evaluated. It is known that the fusion of spinal segments leads to degenerative changes in the mobile segments above or below the fused spine, including sacroiliac joint [31]. Further long-term observation is needed to confirm the clinical efficacy of PLIF using this HAp/Col composite. Despite these limitations, this study has demonstrated that the graft of HAp/Col composite with BMA in a titanium cage facilitated bony fusion in PLIF.

\section{Conclusion}

The HAp/Col composite with BMA demonstrated an excellent fusion rate, which is comparable to that of LBG. This hybrid construct can be effectively used as an alternative to conventional autologous LBG for intervertebral spinal fusion.

\section{Acknowledgements}

We thank Daisuke Shoji for his help with the SEM pictures.

\section{Authors' contributions}

TY analyzed the data and wrote the original draft. $\mathrm{MH}, \mathrm{SE}, \mathrm{TH}, \mathrm{HI}$ acquired the data. $\mathrm{AO}$ validated the paper. $\mathrm{AO}$ supervised the researched. All authors contributed to the writing of the final manuscript. All authors approved the manuscript to be published and agree to be accountable for all aspects of the work in ensuring that questions related to the accuracy or integrity of any part of the work are appropriately investigated and resolved. All authors read and approved the final manuscript.

\section{Funding}

This research was supported by HOYA Technosurgical. The funding bodies played no role in the design of the study, or collection of data.

\section{Availability of data and materials}

The datasets generated and/or analyzed during the current study are available from the corresponding author on reasonable request.

\section{Declarations}

\section{Ethics approval and consent to participate}

The study was approved by the "Ethics committee of Tokyo Medical and Dental University."The reference number was "ref. 1529."We obtained written informed consent from all the patients involved in this study.

\section{Consent for publication}

Not applicable.

\section{Competing interests}

Not applicable.

Received: 13 September 2021 Accepted: 13 October 2021

Published online: 24 October 2021

\section{References}

1. Xiao YX, Chen QX, Li FC. Unilateral transforaminal lumbar interbody fusion: a review of the technique, indications and graft materials. J Int Med Res. 2009;37(3):908-17.

2. Heida K, Ebraheim M, Siddiqui S, Liu JY. Effects on clinical outcomes of grafts and spacers used in transforaminal lumbar interbody fusion: a critical review. Orthop Surg. 2013;5(1):13-7.

3. Banwart JC, Asher MA, Hassanein RS. Iliac crest bone graft harvest donor site morbidity. A statistical evaluation. Spine (Phila Pa 1976). 1995:20(9):1055-60.

4. Wei XT, Egawa S, Matsumoto R, Yasuda H, Hirai K, Yoshii T, Okawa A, Nakajima T, Sotome S. Augmentation of fracture healing by hydroxyapatite/ collagen paste and bone morphogenetic protein-2 evaluated using a rat femur osteotomy model. J Orthop Res. 2018;36(1):129-37.

5. Masaoka T, Yamada T, Yuasa M, Yoshii T, Okawa A, Morita S, Kozaka Y, Hirano M, Sotome S. Biomechanical evaluation of the rabbit tibia after implantation of porous hydroxyapatite/collagen in a rabbit model. J Orthop Sci. 2016;21(2):230-6.

6. Taniyama T, Masaoka T, Yamada T, Wei XT, Yasuda H, Yoshii T, Kozaka Y, Takayama T, Hirano M, Okawa A, et al. Repair of osteochondral defects in a rabbit model using a porous hydroxyapatite collagen composite impregnated with bone morphogenetic protein-2. Artif Organs. 2015;39(6):529-35.

7. Sugata Y, Sotome S, Yuasa M, Hirano M, Shinomiya K, Okawa A. Effects of the systemic administration of alendronate on bone formation in a porous hydroxyapatite/collagen composite and resorption by osteoclasts in a bone defect model in rabbits. J Bone Jt Surg Br. 2011;93B(4):510-6.

8. Maehara H, Sotome S, Yoshii T, Torigoe I, Kawasaki Y, Sugata Y, Yuasa M, Hirano M, Mochizuki N, Kikuchi M, et al. Repair of large osteochondral defects in rabbits using porous hydroxyapatite/collagen ( $\mathrm{HAp} / \mathrm{Col})$ and fibroblast growth factor-2 (FGF-2). J Orthop Res. 2010;28(5):677-86.

9. Nandi SK, Roy S, Mukherjee P, Kundu B, De DK, Basu D. Orthopaedic applications of bone graft \& graft substitutes: a review. Indian J Med Res. 2010;132:15-30.

10. Rihn JA, Kirkpatrick K, Albert TJ. Graft options in posterolateral and posterior interbody lumbar fusion. Spine. 2010;35(17):1629-39.

11. Feng JT, Yang XG, Wang F, He X, Hu YC. Efficacy and safety of bone substitutes in lumbar spinal fusion: a systematic review and network metaanalysis of randomized controlled trials. Eur Spine J. 2020;29(6):1261-76.

12. LeGeros RZ. Properties of osteoconductive biomaterials: calcium phosphates. Clin Orthop Relat R. 2002;395:81-98.

13. Giannoudis PV, Dinopoulos H, Tsiridis E. Bone substitutes: an update. Injury. 2005;36:20-7. 
14. Becker S, Maissen O, Ponomarev I, Stoll T, Rahn B, Wilke I. Osteopromotion by a beta-tricalcium phosphate/bone marrow hybrid implant for use in spine surgery. Spine. 2006;31(9):1065-1065.

15. Yamada T, Yoshii T, Sotome S, Yuasa M, Kato T, Arai Y, Kawabata S, Tomizawa S, Sakaki K, Hirai T, et al. Hybrid grafting using bone marrow aspirate combined with porous beta-tricalcium phosphate and trephine bone for lumbar posterolateral spinal fusion: a prospective, comparative study versus local bone grafting. Spine (Phila Pa 1976). 2012;37(3):E174-9.

16. Tay BK, Le AX, Heilman M, Lotz J, Bradford DS. Use of a collagenhydroxyapatite matrix in spinal fusion. A rabbit model. Spine (Phila Pa 1976). 1998;23(21):2276-81.

17. Neen D, Noyes D, Shaw M, Gwilym S, Fairlie N, Birch N. Healos and bone marrow aspirate used for lumbar spine fusion: a case controlled study comparing healos with autograft. Spine (Phila Pa 1976). 2006;31(18):E636-40.

18. Epstein NE. An analysis of noninstrumented posterolateral lumbar fusions performed in predominantly geriatric patients using lamina autograft and beta tricalcium phosphate. Spine J. 2008;8(6):882-7.

19. Dai LY, Jiang LS. Single-level instrumented posterolateral fusion of lumbar spine with beta-tricalcium phosphate versus autograft: a prospective, randomized study with 3-year follow-up. Spine (Phila Pa 1976). 2008;33(12):1299-304.

20. Ohgushi H, Goldberg VM, Caplan Al. Heterotopic osteogenesis in porous ceramics induced by marrow-cells. J Orthop Res. 1989;7(4):568-78.

21. Muschler GF, Boehm C, Easley K. Aspiration to obtain osteoblast progenitor cells from human bone marrow: the influence of aspiration volume. J Bone Jt Surg Am. 1997;79A(11):1699-709.

22. Connolly J, Guse R, Lippiello L, Dehne R. Development of an osteogenic bone-marrow preparation. J Bone Jt Surg Am. 1989;71A(5):684-91.

23. Neen D, Noyes D, Shaw M, Gwilym S, Fairlie N, Birch N. Healos and bone marrow aspirate used for lumbar spine fusion: a case controlled study comparing healos with autograft. Spine. 2006;31(18):E636-40.

24. Cuzzocrea F, Ivone A, Jannelli E, Fioruzzi A, Ferranti E, Vanelli R, Benazzo F. PEEK versus metal cages in posterior lumbar interbody fusion: a clinical and radiological comparative study. Musculoskelet Surg. 2019;103(3):237-41.

25. Kushioka J, Kaito T, Makino T, Fujiwara H, Tsukazaki H, Takenaka S, Sakai Y, Yoshikawa $\mathrm{H}$. Difference in the fusion rate and bone formation between artificial bone and iliac autograft inside an inter-body fusion cage: a comparison between porous hydroxyapatite/type 1 collagen composite and autologous iliac bone. J Orthop Sci. 2018;23(4):622-6.

26. Williams AL, Gornet MF, Burkus JK. CT evaluation of lumbar interbody fusion: current concepts. AJNR Am J Neuroradiol. 2005;26(8):2057-66.

27. Sandhu HS, Toth JM, Diwan AD, Seim HB 3rd, Kanim LE, Kabo JM, Turner AS. Histologic evaluation of the efficacy of rhBMP-2 compared with autograft bone in sheep spinal anterior interbody fusion. Spine. 2002;27(6):567-75.

28. Cunningham BW, Kanayama M, Parker LM, Weis JC, Sefter JC, Fedder IL, McAfee PC. Osteogenic protein versus autologous interbody arthrodesis in the sheep thoracic spine. A comparative endoscopic study using the Bagby and Kuslich interbody fusion device. Spine. 1999;24(6):509-18.

29. Galimberti F, Lubelski D, Healy AT, Wang T, Abdullah KG, Nowacki AS, Benzel EC, Mroz TE. A systematic review of lumbar fusion rates with and without the use of rhBMP-2. Spine. 2015;40(14):1132-9.

30. Thaler M, Lechner R, Gstottner M, Kobel C, Bach C. The use of beta-tricalcium phosphate and bone marrow aspirate as a bone graft substitute in posterior lumbar interbody fusion. Eur Spine J. 2013;22(5):1173-82.

31. Longo UG, Loppini M, Berton A, Laverde L, Maffulli N, Denaro V. Degenerative changes of the sacroiliac joint after spinal fusion: an evidencebased systematic review. Br Med Bull. 2014;112(1):47-56.

\section{Publisher's Note}

Springer Nature remains neutral with regard to jurisdictional claims in published maps and institutional affiliations.
Ready to submit your research? Choose BMC and benefit from:

- fast, convenient online submission

- thorough peer review by experienced researchers in your field

- rapid publication on acceptance

- support for research data, including large and complex data types

- gold Open Access which fosters wider collaboration and increased citations

- maximum visibility for your research: over $100 \mathrm{M}$ website views per year

At BMC, research is always in progress.

Learn more biomedcentral.com/submissions 